\title{
Design and Analysis of Fuel-Cell Hybrid Systems Oriented to Automotive Applications
}

\author{
Diego Feroldi, Maria Serra, and Jordi Riera
}

\begin{abstract}
Hybridization with high specific energy-storage devices such as supercapacitors (SCs) has important advantages in fuel-cell (FC)-based systems. This paper presents an approach for the design and analysis of FC hybrid systems (FCHSs) oriented to automotive applications. The FCHS is considered to be the most attractive long-term option for propulsion of passenger cars. The design stage includes the determination of the electrical topology and the determination of the hybridization degree (HD) according to drivability conditions. With the selected design, the optimal hydrogen consumption for different driving cycles and the energy flows in the hybrid vehicle are analyzed. The entire study is performed with a detailed model of the FCHS in the Advanced Vehicle Simulator (ADVISOR): the determination of the HD according to drivability requirements, the analysis of the energy flows, and the computation of the optimal hydrogen consumption. The results show that hybridization allows a significant improvement in the hydrogen economy through the recovered energy from breaking. At the same time, the results suggest a conflict between a design according to drivability conditions and a design for the highest efficiency. The conclusion is that hybridization with SCs in FC-based vehicles is a meaningful procedure that enhances performance.
\end{abstract}

Index Terms-Automotive applications, fuel cells (FCs), hybrid vehicles, hydrogen economy, supercapacitors (SCs).

\section{INTRODUCTION}

$\mathbf{F}$ UEL-CELL hybrid systems (FCHSs) are composed of a primary power source, i.e., the FC system (FCS), and an energy-storage system (ESS), e.g., a battery or a supercapacitor (SC) bank, which supplies the load power demand. Given a certain load power $P_{\text {load }}(t)$, this can be supplied with some power from the FCS, i.e., $P_{\mathrm{fcs}}(t)$, where the rest of the power is supplied by the ESS, i.e., $P_{\text {ess }}(t)$. Thus

$$
P_{\text {load }}(t)=P_{\text {fcs }}(t)+P_{\text {ess }}(t) \quad \forall t \text {. }
$$

Fig. 1 shows a diagram with the energy and power flows between the elements in the hybrid system. The power produced by the FC stack is fed with a hydrogen flow from a hydrogenpressurized tank.

Manuscript received November 25, 2008; revised April 15, 2009. First published July 14, 2009; current version published November 11, 2009. This work was supported in part by the Spanish Government and the Department of Universities, Investigation, and Society of Information of the Generalitat de Catalunya under Project CICYT DPI2007-62966. The review of this paper was coordinated by Mr. D. Diallo.

The authors are with the Institut de Robòtica i Informàtica Industrial, Council of Scientific Research of Spain, Universitat Politècnica de Catalunya (CSIC-UPC), 08028 Barcelona, Spain (e-mail: dferoldi@iri.upc.edu; maserra@iri.upc.edu; riera@iri.upc.edu).

Color versions of one or more of the figures in this paper are available online at http://ieeexplore.ieee.org.

Digital Object Identifier 10.1109/TVT.2009.2027241
Four energy flows can be distinguished in the FCHS of Fig. 1: 1) a direct energy flow from the FC to the load; 2) a charging energy flow from the FCS to the ESS; 3) an energy flow from the load to the ESS, e.g., during regenerative braking in automotive applications; and 4) an energy flow from the ESS to the load to boost the FCS operation, supplying energy that has been previously charged from the FCS or regenerated from the load.

Hybridization has important advantages in FC-based vehicles. The potential advantages of a hybrid system are given as follows [1], [2]: 1) reducing the cost and weight of the global system; 2) overcoming the relatively slow FCS transient response; 3) improving the hydrogen economy; and 4) reducing the warm-up time of the FCS to reach full power. Another important advantage is the reduction of the physical constraints applied on the FC, leading to an increase of the FC stack and system durability. While the degradation mechanism is still being investigated, it is possible to assure that the degradation of Pt catalysts is higher with high cell voltages. Thus, hybridization can help operate the FCS in more convenient operating points, avoiding those high cell voltage ranges. Moreover, hybridization can help avoid reactant starvation since the ESS should supply the peak power, and thus, the FCS operation is smoother [3]. The disadvantages of hybridization are a greater complexity of the vehicle and the control system.

The advantages and disadvantages of the FCHSs can be better understood by analyzing the roles of the ESS in an FC hybrid vehicle (FCHV). These roles are given in the list that follows [4].

1) Supply of traction power during FC start-up: Under cold ambient or cold-start conditions, the FCS output power is lower than its rated power. The ESS is expected to compensate this drawback until the FC warms up and reaches its rated power.

2) Power assistance during driving cycles: The stored energy can partially or totally supply the transitory demands of energy, e.g., during acceleration, making it possible to reduce the FC rated power and improve the transient response.

3) Regenerative braking energy recovery: The possibility of recovering energy from regenerative braking in automotive applications allows the improvement of the hydrogen economy recuperating energy that, otherwise, is dissipated at the friction brakes. This amount of energy depends on the driving cycle and is considered to be from $5 \%$ in a highway cycle to almost $18 \%$ in an urban cycle. 


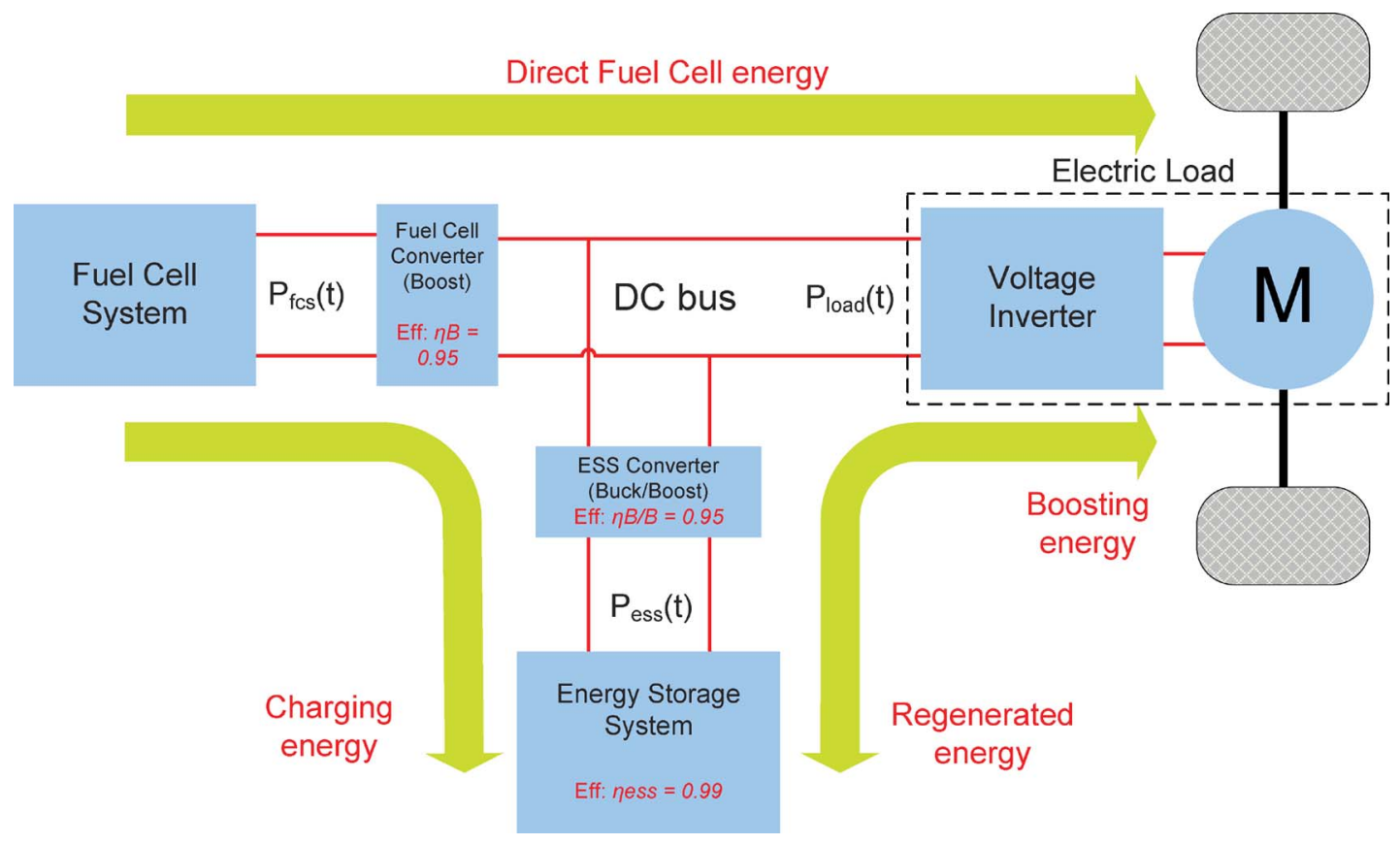

Fig. 1. Diagram showing the electrical topology and the energy and power flows in an FCHS.

4) Supply of electrical accessory loads: An FCHV may include several electric loads such as radiator fans, electric power steering, electric brakes, air conditioning systems, etc., that could be considered as a constant load. It is potentially expected that the ESS could maintain the electrical accessory loads for brief periods during the cycle (e.g., if the FC is shut down).

5) FC start-up and shutdown: In FCHVs, it would be desirable to have FC start/stop capability. This means that, while the vehicle is running, the primary power plant (i.e., the FC) can be shut down and restarted according to an energy-management strategy.

Despite the fact that the FCHS has already been studied in the literature, there is still a necessity for clear analyses motivating the introduction into the society of FC-based vehicles, which is a promising technology in development that has taken on an increasing amount of importance over the past years and is considered to be the most attractive long-term option for passenger cars [5]. Therefore, in this paper, the design and analysis of FC-based systems oriented to automotive applications is addressed. We concentrate our attention on FCHVs because this application is particularly attractive, although some general aspects that were studied also apply to other applications where the load strongly varies, such as stand-alone residential proton exchange membrane FC power systems.

The organization of this paper is given as follows: In Section II, the electrical structures for FCHVs are approached, focusing on the topology and the ESS. In Section III, the FCHV model is presented. In Section IV, an analysis of the energy flows in the FCHV is done. In Section V, the determination of the hybridization degree (HD) according to drivability conditions is assessed. In Section VI, the computation of the optimal hydrogen consumption is performed. Finally, the discussion of the results and the conclusions of this paper are summarized in Sections VII and VIII, respectively.

\section{Electrical Structure For A FUEL-CELl HybRID SYSTEM}

The electrical structure for an FC-based system essentially involves an FC stack with its auxiliary systems and the load, which is generally an ac electrical motor. The FCS by itself is an electrical power source, whose dc output voltage drops with the current according to the polarization curve. Thus, it is necessary to incorporate power converters to convert the voltage from dc to ac and to reach the appropriate voltage level.

The electrical structure for an FCHV also includes an ESS. The ESS can store energy produced by the FC and then delivered to the load. In addition, the ESS can store energy recovered from braking. Therefore, the power converter connected to the ESS must be a bidirectional converter, allowing the energy flow in both directions.

In this section, we approach the design of the electrical structure for an FCHV, focusing on the determination of the electrical topology and the selection of the ESS. The detailed design of the power converters is beyond the scope of this paper.

\section{A. Topology of the Electrical System}

The topology of an electric system is given by the interconnections of the system components. The selection of the most adequate topology is covered in [6]-[9], where different topologies and their appropriate control are analyzed, and the advantages and disadvantages of each case are shown. Thus, several topologies are considered in the literature to connect the ESS and the FCS to the load, depending on the following issues:

1) characteristics of the load ( $\mathrm{dc}$ or ac voltage, single-phase or three-phase, and range of the voltage);

2) possibility of energy recovering from the load (e.g., regenerative braking);

3) range of the voltage in the ESS;

4) output voltage of the FCS. 


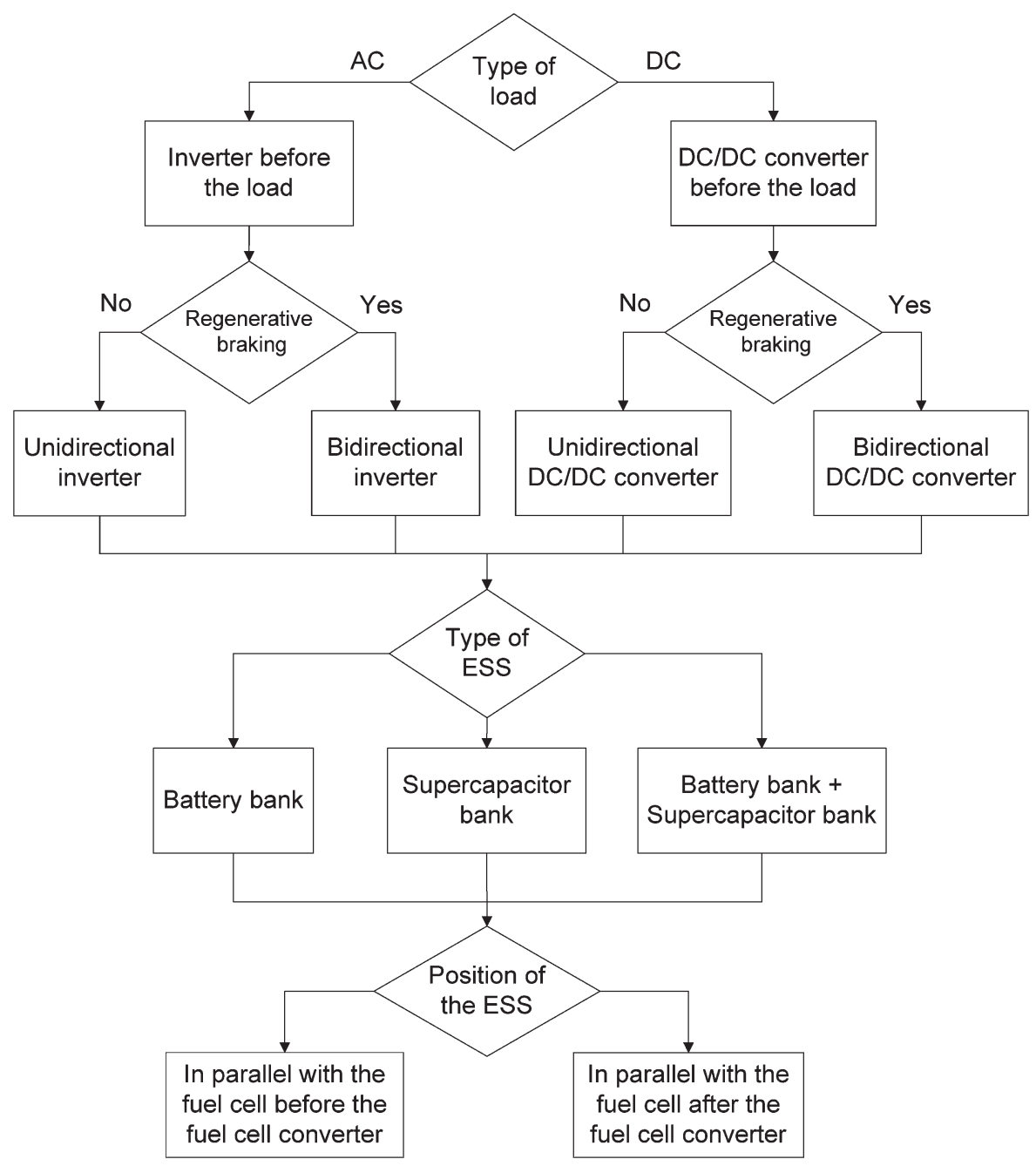

Fig. 2. Design tree for the selection of the electrical structure for the FCHV.

In this paper, a number of choices, as represented by the decision tree shown in Fig. 2, were considered before choosing the topology of the electrical system, which is shown in Fig. 1. The main decision was if the vehicle has regenerative braking. This electrical topology is used as a frame of reference for the analyses of the FCHV throughout this work. In this topology, the FCS is connected to the dc bus through a step-up power converter (boost converter) because the dc voltage bus is normally high voltage, whereas the ESS is connected to the dc bus through a bidirectional power converter (buck-boost converter). With regard to the load, which is an ac induction motor, it is fed through a bidirectional dc-ac inverter that allows the energy flow from regenerative braking.

The power converter that connects the ESS to the dc bus is fundamental in implementing the energy management strategy in the hybrid system: This converter acts as a "switch" that allows the regulation of the energy flow between the ESS and the dc bus. In the same way, the converter that connects the FCS to the dc bus allows the regulation of the power flow from the FCS and, in addition, has to cope with the variations in the FCS output voltage since the FCS does not act as an ideal voltage source.

\section{B. ESS: Batteries and SCs}

The ESS in the FCHS can be implemented either by a high specific energy device such as batteries or by a high specific power device such as SCs. There is also the possibility of a combined solution using batteries and SCs [10]. Before dealing with this analysis, two meaningful parameters concerning the ESS are introduced. First, the HD is the relation between two installed power, namely, the maximum FCS power $P_{\text {fcs, max }}$ and the maximum ESS power $P_{\text {ess,max }}$. We use the following expression for HD:

$$
\mathrm{HD}=\frac{P_{\mathrm{ess}, \max }}{P_{\mathrm{fcs}, \max }+P_{\mathrm{ess}, \max }} \times 100[\%] .
$$

With this definition, a 100\% HD indicates a vehicle without FC (only storage bank), and 0\% HD indicates a pure FC vehicle (no storage bank). Second, the power/ESS ratio $P / E$ is defined as the relationship between the specific power $P$ and the specific energy $E$ of the storage system [11], i.e.,

$$
P / E=\frac{P[\mathrm{~W} / \mathrm{kg}]}{E[\mathrm{Wh} / \mathrm{kg}]}[\mathrm{W} / \mathrm{Wh}] .
$$


TABLE I

Characteristics OF RELEVANT EXAMPLES OF THE ESS

\begin{tabular}{|l|c|c|c|}
\hline & $\begin{array}{c}\mathrm{P} / \mathrm{E} \\
{[W / W h]}\end{array}$ & $\begin{array}{c}\text { Specific } \\
\text { power } \\
{[W / \mathrm{kg}]}\end{array}$ & $\begin{array}{c}\text { Specific } \\
\text { energy } \\
{[W h / \mathrm{kg}]}\end{array}$ \\
\cline { 1 - 3 } $\begin{array}{l}\text { High power lead-acid } \\
\text { batteries }\end{array}$ & \multirow{2}{*}{10} & 300 & 30 \\
\cline { 1 - 3 } Ni-Mh batteries & $>100$ & $4-500$ & $50-70$ \\
\hline Supercapacitors & up to 1000 & up to 5 \\
\hline
\end{tabular}

Some relevant examples are collected from the literature [11] and reported in Table I. For some SCs on the market, such as the model BCAP0350 from Maxwell Technologies [12], the specific power is $3900 \mathrm{~W} / \mathrm{kg}$, and a recent study with asymmetric double-layer SCs has reported advances in specific energy approaching $40 \mathrm{Wh} / \mathrm{kg}$ [13].

We chose SCs in this paper because they are more attractive for applications with low energy and high power demand, particularly at low temperatures, although the cost may remain an obstacle. SCs can be deep charged-discharged at high rates for 500 000-1 000000 cycles with a relatively small change in characteristics (10\%-20\% of degradation in capacitance and resistance) and with high charge-discharge efficiency [14]. However, batteries and SCs do not compete but are complementary in the development of hybrid electric vehicles (HEVs) because of the high specific energy of the former and the high specific power of the latter, notwithstanding the significantly longer cycle life of SCs (more than two orders of magnitude [15]).

Different types of HEVs require ESSs that are characterized by different specific power and energy values, $P / E$ ratios, and cycle lives. In Gao [16], two FCHVs are studied, comparing an FC-battery hybrid power train and an FC-SC hybrid power train. The conclusion is that the second option is better since SCs can more effectively assist the FC to meet the transient power demand. Since SCs have high specific power, they can supply great quantities of instantaneous power, allowing boosting the FC in power-demanding situations, such as fast acceleration or climbing. Although the study of Gao is done with the FC-battery hybrid power train composed of lead-acid batteries instead of other types of batteries with higher specific power (e.g., Li-ion or $\mathrm{Ni}-\mathrm{MH}$ ), the general conclusion is still valid because of the exceptional specific power of SCs. In [17], analyzing the requirements of batteries for city hybrid buses, it is remarked that, to get a really significant fuel consumption improvement, it is essential to be able to recover a good percentage of the available energy during regeneration, and to that end, devices with high power-recharge capability are required.

With regard to the lifetime, it is concluded that actual batteries are not good for automotive applications. However, some modifications in the chemistry of conventional lead-acid batteries are currently being developed to operate in a highrate partial-state-of-charge mode with acceptable performance [18]. There are also ultrabatteries in development, which are hybrid energy storage devices combining an asymmetric SC and a lead-acid battery in one unit, taking advantage of the best from both technologies without the need for extra electronic controls [19].
TABLE II

Vehicle Specifications in the Vehicle Model

\begin{tabular}{lll}
\hline Specification & Symbol & Value \\
\hline Vehicle mass $^{\mathrm{a}}$ & $M$ & $882 \mathrm{~kg}$ \\
Frontal area & $A_{f}$ & $2 \mathrm{~m}^{2}$ \\
Drag coefficient & $C_{d}$ & 0.335 \\
Coefficient of rolling friction & $f_{r}$ & 0.009 \\
\hline \multicolumn{2}{l}{ a Vehicle mass without taking into account the FCS mass and the ESS } \\
mass.
\end{tabular}

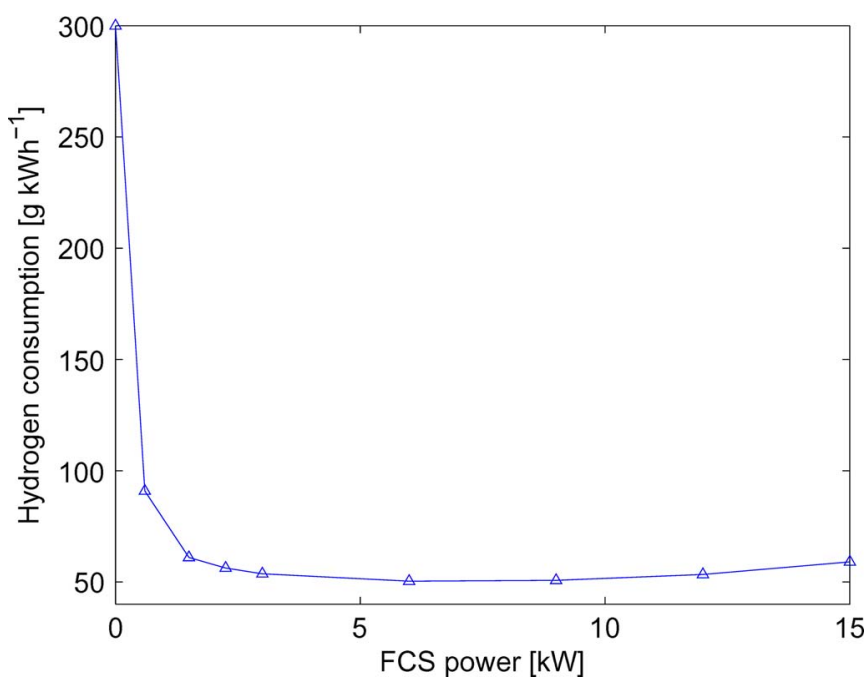

Fig. 3. Hydrogen consumption map of the FCS from the ADVISOR model.

\section{Fuel-Cell Hybrid Vehicle Model}

To study FCHVs, it is necessary to rely on accurate and practical models to describe the system behavior. The Advanced Vehicle Simulator (ADVISOR) [20], [21] is a system analysis tool for vehicle modeling created by the National Renewable Energy Laboratory (USA) in the MATLAB/Simulink environment. It provides a flexible and robust set of models, data, and script text files, which are used to quantify the fuel economy, the performance, and the emissions of vehicles that use alternative technologies, including FCs, batteries, SCs, electric motors, and internal combustion engines in hybrid configurations. The component models of this toolbox are used in several works concerning FCHVs, e.g., [16] and [22]-[24].

The component models are quasi-static and cannot be used alone to predict phenomena with very small timescales (lower than a second). In general, the component models are empirical models based on test data. With regard to the FC power system, ADVISOR includes two empirically based modeling options: 1) a model that lumps the entire FCS into a system efficiency map as a function of net output power and 2) a second model where the FC performance is characterized with a polarization curve, the associated hydrogen usage per cell, and the number of cells within the stack. ADVISOR was originally developed as an analysis tool, and in this paper, ADVISOR has been used in the design process by iterative evaluation.

In this paper, we consider the performance of an FCHV based on a small car and the entire system being modeled in ADVISOR according to the principal parameters listed in Table II. The total vehicle mass will be determined after the 


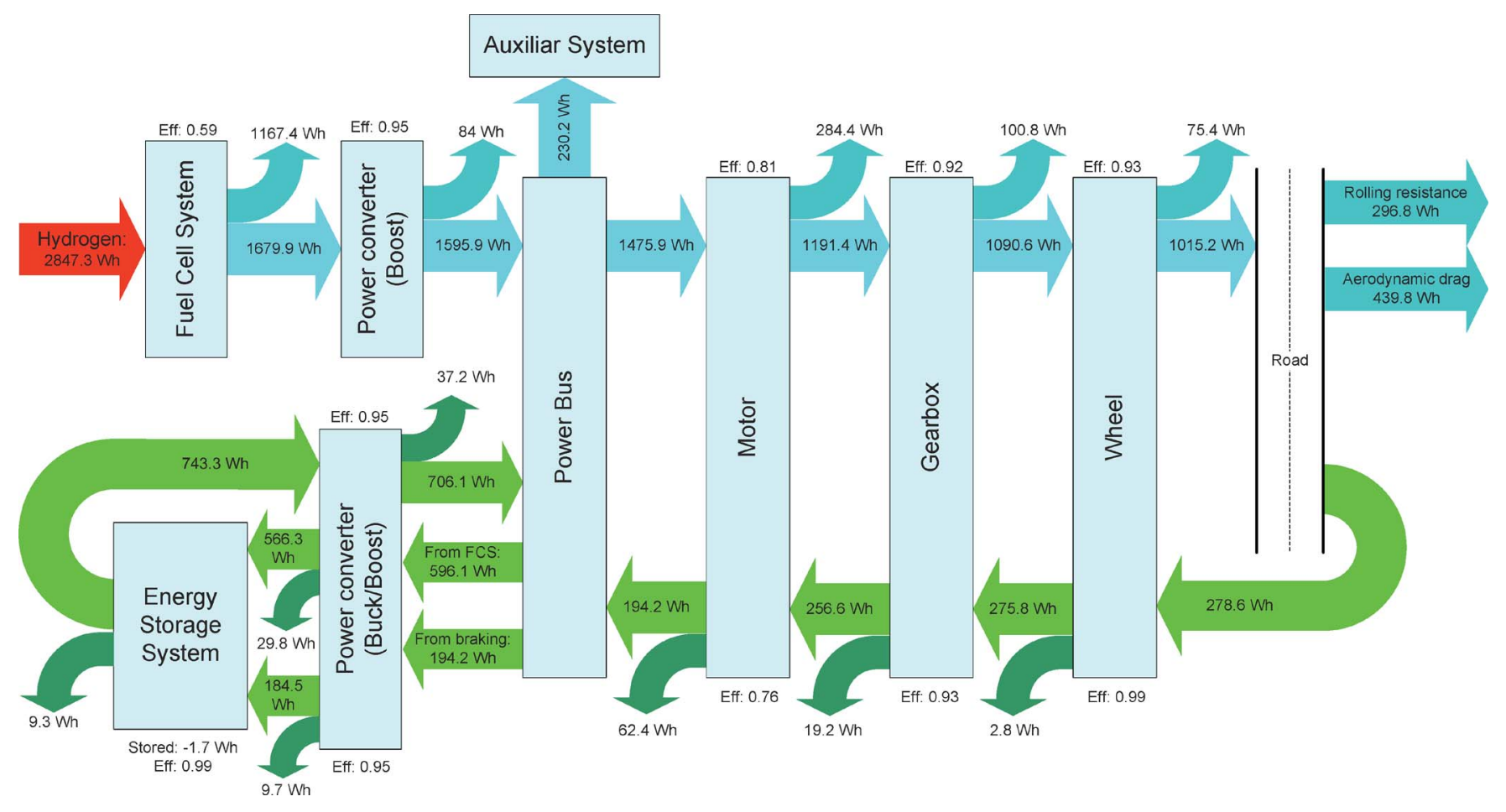

Fig. 4. Energy flows in the FCHV running on NEDC.

TABLE III

ENERGY FLOW SUMMARY IN A 1380-kg FCHV

\begin{tabular}{|l|c|c|c|c|c|c|c|c|}
\hline \multirow{2}{*}{} & \multicolumn{2}{|c|}{ NEDC } & \multicolumn{2}{c|}{ UDDS } & \multicolumn{2}{c|}{ FTP } & \multicolumn{2}{c|}{ HWFET } \\
\cline { 2 - 10 } & {$[W h]$} & {$[\%]$} & {$[W h]$} & {$[\%]$} & {$[W h]$} & {$[\%]$} & {$[W h]$} & {$[\%]$} \\
\hline Hydrogen energy & 2847 & 100 & 2957 & 100 & 4416 & 100 & 4141 & 100 \\
\hline FCS energy out & 1680 & 59 & 1744 & 59 & 2605 & 59 & 2442 & 59 \\
\hline FCS losses & 1167 & 41 & 1213 & 41 & 1811 & 41 & 1699 & 41 \\
\hline Motor energy in $^{*}$ & 1476 & 51.8 & 1611 & 54.5 & 2419 & 54.8 & 2148 & 51.8 \\
\hline Total losses in power mode $^{\mathrm{a}}$ & 461 & 16.2 & 538 & 18.2 & 775 & 17.5 & 622 & 15 \\
\hline Total losses in regenerative mode $^{\mathrm{b}}$ & 84 & 3.0 & 144 & 4.9 & 202 & 4.6 & 39 & 0.9 \\
\hline Recovered energy from braking & 194 & 6.8 & 310 & 10.5 & 452 & 10.2 & 86 & 2.1 \\
\hline Rolling resistance energy & 297 & 9.4 & 326 & 11 & 482 & 10.9 & 448 & 10.8 \\
\hline Aerodynamic drag energy & 444 & 15.4 & 293 & 9.9 & 508 & 11.5 & 953 & 23 \\
\hline
\end{tabular}

The $\%$ column refers to the percentage of energy with respect to the hydrogen energy.

${ }^{a}$ The total losses in power mode are the summation of the losses in the direct path from the FCS to the wheels.

$\mathrm{b}$ The total losses in regenerative mode are the summation of the losses in the path from the wheels to the ESS

dimensioning process of the FCS and the ESS. In this platform, the vehicle is modeled in detail, taking into account the several components that compose the vehicle (e.g., FCS, wheel and axle, final drive, gearbox, and clutch) and including the power converter losses to achieve a more realistic model.

The FCS consists of the FC stack and the auxiliary system, a set of devices necessary for the FCS operation that includes a compressor, cooling/heating devices, and a water-management system. Among the auxiliary components, the compressor is the one with larger power consumption (up to $93.5 \%$ of the total auxiliary power consumption [25]). The most relevant characteristic of the FCS, with major impact on the performance, is the hydrogen consumption map: the relation between the delivered power and the hydrogen consumption (see Fig. 3).

Given that, in the HD analysis, it is necessary to account for models representing FCSs of different sizes, it is needed to scale the original model to represent FCSs with different rated power. Kim et al. [25] concluded that it is possible to linearly scale the efficiency map of the FCS. This conclusion is reinforced in Ahluwalia et al. [26], where four FCSs with different rated power in study are also linearly scaled, as well as the way that the ADVISOR toolbox works.

\section{Analysis of the Energy Flows in THE Fuel-CEll Hybrid Vehicle}

It was mentioned that, in an FCHV, there are four principal energy flows. Getting into more detail, Fig. 4 depicts the energy flow from the hydrogen tank toward the wheels through the power bus, the electric motor, and the gearbox. The numbers in the arrows correspond to the total energy transferred between components or to the total losses in each component along the load profile in study. Each component has its own losses, except the power bus, which is considered ideal. Thus, the initial amount of energy from the hydrogen tank is degraded. In addition, the vehicle employs energy to overcome the rolling resistance and the aerodynamics drag force. In the same figure, the wheel-to-ESS flow, i.e., the energy flow from regenerative 
braking to the ESS, is also represented, which also diminishes due to the losses in the components.

As mentioned before, the amount of energy that it is possible to recover from regenerative braking depends on the particular driving cycle. The standard driving cycles are widely utilized in the literature to evaluate the performance of a given FCHV. These standardized speed profiles, representing urban and highway scenarios, were originally stated for measuring pollutant emissions and the gasoline economy of engines [27] and are useful to evaluate the performance and to assess the HD in the FCHV. In this paper, the analysis is performed with four standard driving cycles: 1) the New European Driving Cycle (NEDC); 2) the Urban Dynamometer Driving Schedule (UDDS), which is also known as the Federal Urban Driving Schedule (FUDS); 3) the Federal Test Procedure (FTP); and 4) the Highway Fuel Economy Cycle (HWFET).

Our results show that, for an FCHV according to the parameters of Table II and for a total vehicle mass of $1380 \mathrm{~kg}$, the maximum recoverable energy after considering all the losses represents $7.6 \%$ of the hydrogen energy that is spent to fulfill the NEDC cycle, whereas in the case of UDDS and FTP, it represents $11.7 \%$ and $11.4 \%$, respectively. On the other hand, in a highway cycle such as HWFET, the regenerative braking energy only represents $2.3 \%$ of the hydrogen energy. Some works report greater ratios of energy recovery for a similar vehicle. For example, in [26], it is reported that, in the NEDC cycle with a similar vehicle, the braking energy is $35 \%$ of the traction energy, whereas with the UDDS cycle, the braking energy is up to $50 \%$. Nevertheless, these ratios only account for the energy available at the wheels. If the losses in the internal components, where the energy passes through, are taken into account, the braking energy available at the storage system is much lower. It is also important to note that all these ratios are calculated in the limit situation where no friction brakes are used, allowing the maximum energy recuperation. Thus, these ratios only represent a superior limit, and in real situations, the available energy that can be stored may be lower. Table III summarizes the main values of the energy flow analysis for the four cycles in study.

\section{Determination of the Hybridization Degree ACCORDING TO DRIVABILITY CONDITIONS}

To be competitive with conventional vehicles, FCHVs must satisfy different types of driving conditions. This means that, both in transitory and sustained driving conditions, the power balance between the load and the power sources must be satisfied. In that sense, Ahluwalia et al. [26] stated that the hybrid system must satisfy the following requirements: First, the FCS by itself must be capable of supporting time-sustained driving conditions. This includes two different tests, namely, a top speed test, where a specified speed is sustained, and a grade test, where the vehicle must sustain a determined speed with a determined grade and a certain overweight. Second, with the assistance of the ESS, the hybrid system must fulfill a response time with certain acceleration.

Assuming the drivability requirements and exploiting the FCHV model developed in the ADVISOR environment, it is
TABLE IV

Results From the ANALYsis of the Optimal Hydrogen ECONOMY FOR A VEHICLE OF $1109 \mathrm{~kg}$

\begin{tabular}{|c|c|c|c|c|}
\hline & NEDC & UDDS & FTP & HWFET \\
\hline $\begin{array}{l}\text { Hydrogen } \\
\text { consumption }[g]\end{array}$ & 77 & 80 & 119 & 111 \\
\hline $\begin{array}{l}\text { Hydrogen } \\
\text { consumption }[\mathrm{g} / \mathrm{km}]\end{array}$ & 7.0 & 6.6 & 6.7 & 6.7 \\
\hline $\begin{array}{l}\text { Braking recovery } \\
\text { energy }[W h]\end{array}$ & 194.2 & 310.4 & 452.4 & 85.8 \\
\hline $\begin{array}{l}\text { Braking/hydrogen } \\
\text { ratio }^{\text {a }}[\%]\end{array}$ & 7.6 & 11.7 & 11.4 & 2.3 \\
\hline
\end{tabular}

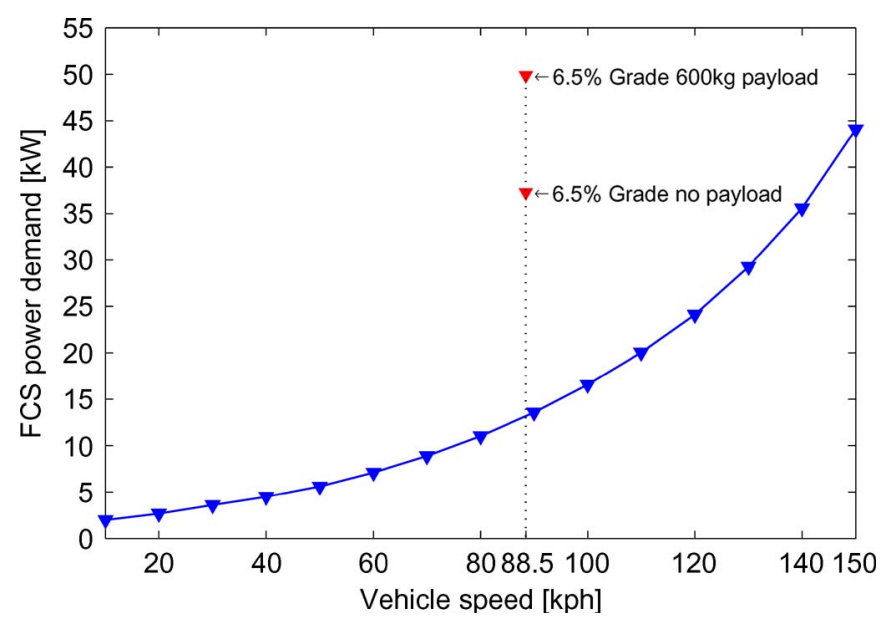

Fig. 5. Power demand versus vehicle sustained speed for a 1380-kg vehicle.

possible to quantify the amount of power that the power train needs to supply to fulfill the traction requirements. In Table IV, the power demands to fulfill each traction power requirement are presented. These power demands correspond to a vehicle with a total mass of $1380 \mathrm{~kg}$. In addition, Fig. 5 shows the power demand to maintain different sustained speeds and the power demand to maintain a sustained speed of $88.5 \mathrm{~km} / \mathrm{h}$ with a grade of $6.5 \%$.

The HD analysis according to drivability conditions consists of determining the FCS rated power and the amount of SCs in the ESS necessary to fulfill the previously stated requirements in Table IV. Once these two design variables are determined, it is possible to calculate the total mass of the vehicle as the summation of the mass of the FCS, i.e., $m_{\mathrm{FCS}}$, the mass of the ESS, i.e., $m_{\mathrm{ESS}}$, and the mass of the basic vehicle, i.e., $m_{\text {veh, basic }}$. Thus

$$
m_{\mathrm{veh}, \mathrm{total}}=m_{\mathrm{ess}}+m_{\mathrm{fcs}}+m_{\mathrm{veh}, \mathrm{basic}} .
$$

The mass of the basic vehicle is the mass of the vehicle without the FCS and the ESS (i.e., without the power train), but it is not a constant mass. It depends on the chosen FCS because the mass of the auxiliary system in the vehicle depends on the rated power of the FCS.

The first step of this dimensioning process concerns the timesustained conditions. The dimensioning process starts with the calculation of the minimum necessary FCS rated power that a vehicle of that mass needs to meet the top sustained speed requirement. Then, the process continues with the calculation 


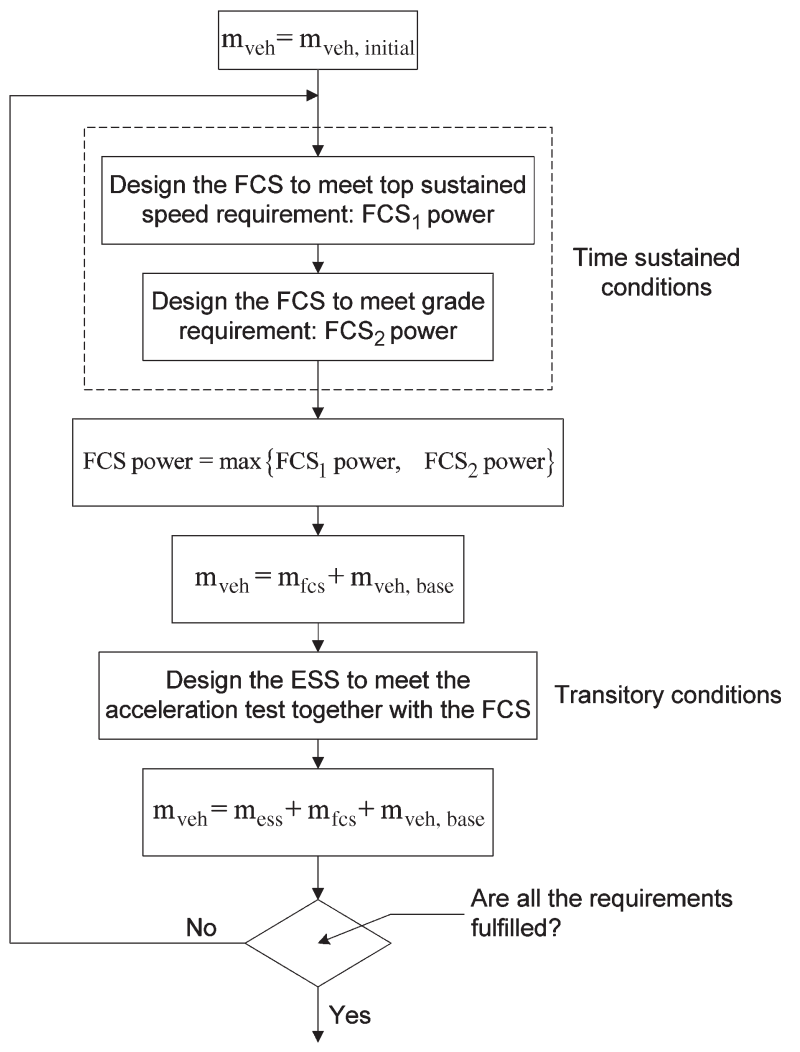

Fig. 6. Schematic of the HD analysis according to drivability requirements.

of the minimum necessary FCS that the vehicle needs to meet the grade requirement. Both estimations are done using only the FCS to power the vehicle because it is a sustained power that can only be supported by the FCS. The FCS that fulfils the two requirements is the maximum value between the two results. Then, the vehicle mass is calculated according to the mass of this FCS using (4). In this step, $m_{\mathrm{ess}}$ is assumed to be null.

The second step is related to the acceleration test and consists of the determination of the minimum amount of SCs in the ESS that is necessary to be added to the previous FCS to reach the acceleration requirement. Once this is done, the total mass is recalculated according to the determined number of SCs using (4).

The procedure is repeated from the first step using the vehicle mass calculated in the last step until the results converge in a combination of the FCS and the ESS such as the vehicle being capable to meet both the sustained and transitory driving conditions. Fig. 6 shows a schematic of the preceding method.

The results show that the minimum FCS is $35 \mathrm{~kW}$ and that the minimum SC bank is 130 modules. Each module in the ADVISOR model has a specific power of $2.5 \mathrm{~kW} / \mathrm{kg}$ and a specific energy of $6 \mathrm{Wh} / \mathrm{kg}$ with a mass of $0.408 \mathrm{~kg}$. Thus, the maximum energy in the bank is $318.2 \mathrm{Wh}$, and the final total mass of the vehicle results in $1109 \mathrm{~kg}$.

However, this is the minimum value of the FCS, and there is still a degree of freedom in the final selection between two extreme cases: 1) the case with a $35-\mathrm{kW}$ FCS and a 130-module bank and 2) the pure FCS case (with a larger FCS and no ESS), where all the power needed is supplied by the FCS. Therefore, an analysis is performed by varying the ESS module number (i.e., varying the HD) and for different driving cycles to find the optimal combination in terms of minimum hydrogen consumption and vehicle mass.

The results of hydrogen economy and total mass, as shown in Figs. 7 and 8, reveal that the best option, i.e., with lower mass of the vehicle and lower hydrogen consumption, is the vehicle consisting of an FCS of $35 \mathrm{~kW}$ and an ESS bank of 130 modules. In this case, the mass of the total vehicle results to be $1109 \mathrm{~kg}$, and the HD is $79 \%$. With regard to Fig. 7, the hydrogen consumption is optimal. The computation of this optimal hydrogen consumption is done using the analysis of the optimal hydrogen consumption formulated in the following section.

\section{Computation of the Optimal Hydrogen CONSUMption in the Fuel-CEll Hybrid Vehicle}

It is useful to determine the minimum amount of hydrogen that a specified vehicle needs to achieve a given driving speed profile. The result of this analysis can be used to compare the performance of the energy management strategies that command the FCS operation [28]. In some works, e.g., [23], [29], and [30], this minimum value is determined through the use of the dynamic programming (DP) technique, which is a procedure that allows calculating a global optimal operation of the system for a given load profile by evaluating all possible control sequences in a systematic way [29] or through the use of the optimal control theory [31]. However, a disadvantage of the DP technique is the relatively long computation time due to the large required grid density. The grid is the result of the discretization of time and the state variables in appropriate grid levels. The grid density should be taken high because it influences the accuracy of the result. On the other hand, the disadvantage of optimal control methods is that the problem is often extremely difficult to solve, particularly for problems that span large time intervals or problems with constraints.

In this paper, we propose a method to determine the minimum hydrogen consumption with a reduced computational cost because it avoids the discretization of the state variables. Only the time is discretized because the standard driving cycles are defined every $1 \mathrm{~s}$. The procedure is based on five assumptions.

1) The capacity of storage in the ESS is sufficient to recover all the available energy from regenerative braking.

2) The friction brake is not employed during the entire cycle.

3) When the power consumption is null, the FCS is turned off.

4) The FCS is already hot at the nominal operating temperature when the cycle starts.

5) The total vehicle mass $m_{\mathrm{veh}}$ is $1109 \mathrm{~kg}$.

A simulation is performed for each driving cycle in such a way that the FCS alternately works in two operating points, namely, "ON" and "OFF," according to the actual state of energy (SoE). The SoE is defined as follows:

$$
\operatorname{SoE}(k)=\frac{E(k)}{E_{\text {cap }}} \times 100[\%]
$$

where $E_{\text {cap }}$ is the maximum energy that the storage system is capable of storing, and $k=1,2, \ldots, N$ is the time instant with 


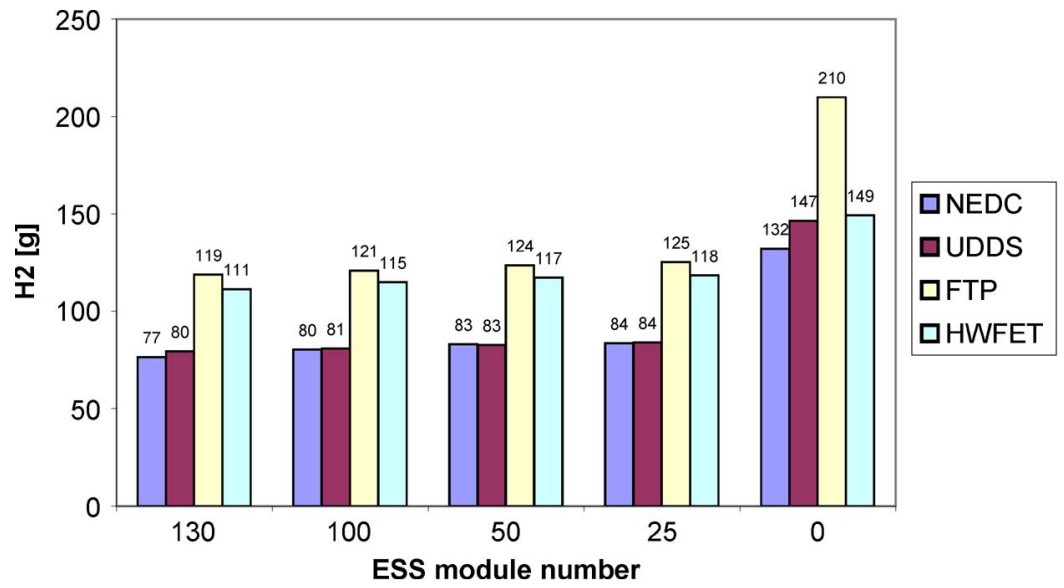

Fig. 7. Hydrogen consumption for different ESS module numbers.

पMass of the vehicle without the FCS and the ESS DMass of the FCS DMass of the ESS

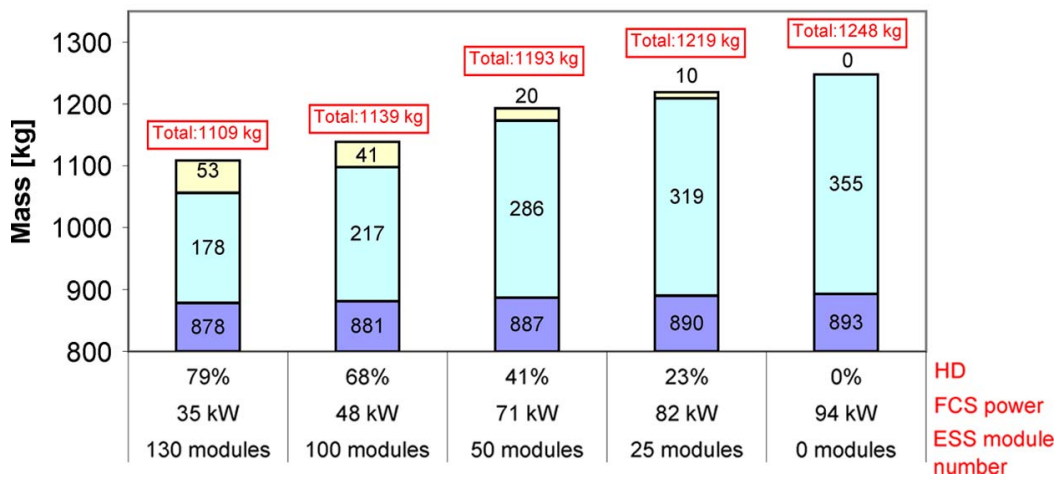

Fig. 8. Total vehicle mass varying the HD (FCS power and ESS module number).

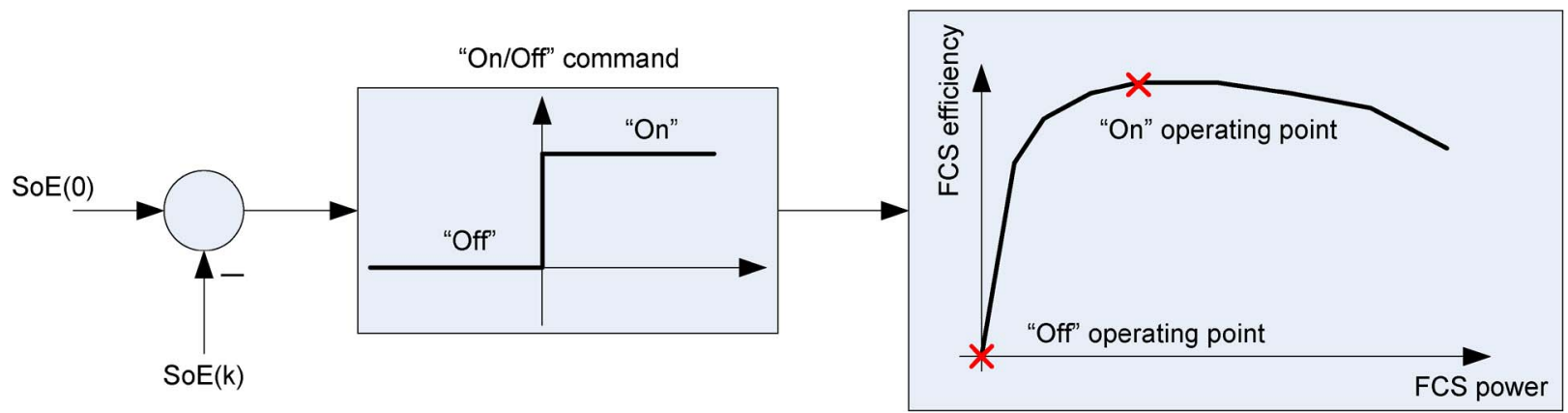

Fig. 9. Scheme showing the ON/OFF operation of the FCS model to perform the analysis of the minimum hydrogen consumption.

the sampling time $\Delta T=1 \mathrm{~s}$. The procedure is given in the list that follows.

1) When $\operatorname{SoE}(k) \leq \operatorname{SoE}(0)$, the FCS is operated at its point of maximum efficiency (the "ON" point).

2) When $\operatorname{SoE}(k)>\operatorname{SoE}(0)$, the FCS is turned off (the "OFF" point).

As a result, the final state of energy $\operatorname{SoE}(N)$ is the same as the initial state of energy $\operatorname{SoE}(0)$.

Thus, the hydrogen consumption only accounts for the necessary hydrogen to fulfill the cycle of duration $N$. The advantages of this method are considered in Section VII. Fig. 9 shows a scheme with the FCS operation to perform the previously described calculation, and the results are collected in Table V, where the braking/hydrogen ratio is defined as the ratio be- tween the energy recovered from braking in the ESS and the energy of the hydrogen, which is calculated from the low heating value of hydrogen that is consumed in the FCS during the cycle.

Since in this analysis the FCS is either working at the point of maximum efficiency or turned off (with the assumption that, when the FCS is turned off, the power consumption is null), the calculation of the minimum consumption is guaranteed.

\section{DISCUSSION}

From the preceding simulation results, it is possible to derive some observations. First, from the design process explained in Section V, it is remarkable that, despite the fact that the rated power of the resulting FCS is $35 \mathrm{~kW}$, the power demand is 
TABLE V

RESUlts From the ANALYSIS OF THE OptimAL HydROGEN ECONOMY FOR A 1109-kg VEHICLE

\begin{tabular}{|c|c|c|c|c|}
\hline & NEDC & UDDS & FTP & HWFET \\
\hline $\begin{array}{l}\text { Hydrogen } \\
\text { consumption }[g]\end{array}$ & 77 & 80 & 119 & 111 \\
\hline $\begin{array}{l}\text { Hydrogen } \\
\text { consumption }[\mathrm{g} / \mathrm{km}]\end{array}$ & 7.0 & 6.6 & 6.7 & 6.7 \\
\hline $\begin{array}{l}\text { Braking recovery } \\
\text { energy }[W h]\end{array}$ & 194.2 & 310.4 & 452.4 & 85.8 \\
\hline $\begin{array}{l}\text { Braking/hydrogen } \\
\text { ratio }^{\mathrm{a}}[\%]\end{array}$ & 7.6 & 11.7 & 11.4 & 2.3 \\
\hline
\end{tabular}

quite lower in the standard driving cycles most of the time. In fact, in NEDC, FTP, and UDDS, the most common demands are in the range from 0 to $15 \mathrm{~kW}$, whereas in HWFET, the power demand is concentrated around $12.5 \mathrm{~kW}$. Thus, the FCS is often disadvantageously working, particularly in NEDC and UDDS, since the efficiency is low in this range. Consequently, there is a conflict between drivability and efficiency because the minimum FCS size to accomplish drivability is too high and does not permit operation at the more efficient FCS range for the most common demands.

Second, from the analysis of Sections IV and VI, the high percentage of recoverable energy from braking in the urban driving cycles (NEDC, UDDS, and FTP), as assessed by the braking/hydrogen ratio in Table $\mathrm{V}$, is noticeable. This ratio is a good indicator of the amount of energy that is actually reused since the model is developed into detail and all the losses in the components of the vehicle are taken into account. In contrast, the parameter that is used to indicate the recovered braking energy in [26] is a fraction of the traction energy and, consequently, is much higher. However, this parameter does not indicate the fraction of the energy from hydrogen that is really regenerated.

\section{CONCLUSION}

In this paper, the design and analysis of FCHSs oriented to automotive applications has been addressed. First, the advantages of this kind of power systems are analyzed, focusing on the mechanism that allows the improvement of the efficiency of FCHVs. Then, the electrical structures for FCHVs are addressed, analyzing the electrical topology, comparing two types of energy-storage devices (batteries and SCs). The conclusion is that SCs seem the best technical alternative nowadays, because FCHVs require storage systems with high specific power and high cycle durability.

The main conclusions of this paper are given in the list that follows.

1) Using a detailed model in ADVISOR to perform a precise study of the system, the result shows that, through hybridization, it is possible to significantly improve the hydrogen economy in FCHVs compared with the pure FC case without SCs (Fig. 7): $41.7 \%$ on NEDC, $45.6 \%$ on UDDS, $43.3 \%$ on FTP, and $22.5 \%$ on HWFET. This is possible because of the reduction on the total mass of the vehicle, the more efficient operation of the FCS, and the energy recovery from braking.

2) In the determination of the HD, there is a conflict between drivability and efficiency, which means that the most robust design to fulfill drivability requirements is not the most efficient in terms of hydrogen economy.

3) The braking/hydrogen ratio defined in Section VI is a more realistic indicator that other parameters are used in the literature to analyze the reduction of the hydrogen consumption due to regenerative braking. It shows that is possible to recover up to $7.6 \%$ of the hydrogen energy on NEDC, $11.7 \%$ on UDDS, $11.4 \%$ on FTP, and $2.3 \%$ on HWFET.

The main contributions stem from three methodologies proposed to design and analyze FCHSs. First, an iterative and systematic methodology to determine the HD to fulfill drivability requirements was elaborated. Second, a new method to assess the optimal hydrogen consumption with a low computational cost that avoids the discretization of the state variables was presented. This method was demonstrated to be useful for evaluating the performance of any energy-management strategy because it provides a benchmark to compare the hydrogen consumption of each strategy. Third, an analysis of the energy flows inside the FCHV was done. The conclusion of this analysis is that the fraction of energy from regenerative braking is relevant to the performance of the FCHV and the assessment of the HD.

\section{ACKNOWLEDGMENT}

The authors would like to thank the Fuel Cells Laboratory, Institut de Robòtica i Informàtica Industrial.

\section{REFERENCES}

[1] K. Jeong and B. Oh, "Fuel economic and life-cycle cost analysis of a fuel cell hybrid vehicle," J. Power Sources, vol. 105, no. 1, pp. 58-65, Mar. 2002.

[2] P. Rodatz, G. Paganelli, A. Sciarretta, and L. Guzzella, "Optimal power management of an experimental fuel cell/supercapacitors-powered hybrid vehicle," Control Eng. Practice, vol. 13, no. 1, pp. 41-53, Jan. 2004.

[3] Y. Shao, G. Yin, and Y. Gao, "Understanding and approaches for the durability issues of Pt-based catalysts for PEM fuel cell," J. Power Sources, vol. 171, no. 2, pp. 558-566, Sep. 2007.

[4] T. Markel, M. Zolot, K. Wipke, and A. Pesaran, "Energy storage system requirements for hybrid fuel cell vehicles," in Proc. 3rd Int. Adv. Autom. Battery Conf., Jun. 10-13, 2003, pp. 1-4.

[5] R. Helmolt and U. Eberle, "Fuel cell vehicles: Status 2007," J. Power Sources, vol. 165, no. 2, pp. 833-843, Mar. 2007.

[6] K. Rajashekara, "Propulsion system strategies for fuel cell vehicles," in Fuel Cell Technology for Vehicles. Warrendale, PA: Soc. Automotive Eng., 2000, pp. 179-187.

[7] A. Drolia, P. Jose, and N. Mohan, "An approach to connect ultracapacitor to fuel cell powered electric vehicle and emulating fuel cell electrical characteristics using switched mode converter," in Proc. Ind. Electron. Soc., 2003, vol. 1, pp. 897-901.

[8] K. Rajashekara, "Power conversion and control strategies for fuel cell vehicles," in Proc. Ind. Electron. Soc., 2003, vol. 3, pp. 2865-2870.

[9] E. Santi, D. Franzoni, A. Monti, D. Patterson, and N. Barry, "A fuel cell based domestic uninterruptible power supply," in Proc. Appl. Power Electron. Conf. Expo., 2002, pp. 605-613.

[10] W. Henson, "Optimal battery/ultracapacitor storage combination," J. Power Sources, vol. 179, no. 1, pp. 417-423, Apr. 2008.

[11] G. Pede, A. Iacobazzi, S. Passerini, A. Bobbio, and G. Botto, "FC vehicle hybridisation: An affordable solution for an energy-efficient FC powered drive train," J. Power Sources, vol. 125, no. 2, pp. 280-291, Jan. 2004. 
[12] Maxwell Technologies, Electrical Double Layer Capacitor: Boostcap Ultracapacitor Series: BPAK2006, Mar. 20. [Online]. Available: http:// www.maxwell.com/ultracapacitors/index.asp

[13] C. Arbizzani, M. Biso, D. Cericola, M. Lazzari, F. Soavi, and M. Mastragostino, "Safe, high-energy supercapacitors based on solventfree ionic liquid electrolyte," J. Power Sources, vol. 185, no. 2, pp. 15751579, Dec. 2008.

[14] A. Burke, "Ultracapacitors: Why, how, and where is the technology," J. Power Sources, vol. 91, no. 1, pp. 37-50, Nov. 2000.

[15] M. Mastragostino and F. Soavi, "Strategies for high-performance supercapacitors for HEV," J. Power Sources, vol. 174, no. 1, pp. 89-93, Nov. 2007.

[16] W. Gao, "Performance comparison of a fuel cell-battery hybrid powertrain and a fuel cell-ultracapacitor hybrid powertrain," IEEE Trans. Veh. Technol., vol. 54, no. 3, pp. 846-855, May 2005.

[17] M. Kellaway, "Hybrid buses-What their batteries really need to do," J. Power Sources, vol. 168, no. 1, pp. 95-98, May 2007.

[18] P. Moseley, B. Bonnet, A. Cooper, and M. Kellaway, "Lead-acid battery chemistry adapted for hybrid electric vehicle duty," J. Power Sources, vol. 174, no. 1, pp. 49-53, Nov. 2007.

[19] L. Lam, R. Louey, N. Haigh, O. Lim, D. Vella, C. Phyland, L. Vu, J. Furukawa, T. Takada, D. Monma, and T. Kano, "VRLA ultrabattery for high-rate partial-state-of-charge operation," J. Power Sources, vol. 174, no. 1, pp. 16-29, Nov. 2007.

[20] K. Wipke, M. Cuddy, and S. Burch, "ADVISOR 2.1: A user-friendly advanced powertrain simulation using a combined backward/forward approach," IEEE Trans. Veh. Technol., vol. 48, no. 6, pp. 1751-1761, Nov. 1999.

[21] T. Markel, A. Brooker, T. Hendricks, V. Johnson, K. Kelly, B. Kramer, M. O'Keefe, S. Sprik, and K. Wipke, "ADVISOR: A system analysis tool for advanced vehicle modeling," J. Power Sources, vol. 110, no. 2, pp. 255-266, Aug. 2002.

[22] D. Candusso, E. Roullière, and E. Toutain, "A fuel cell hybrid power source for a small electric vehicle," Rev. Energ. Ren., Power Eng., vol. 1, no. 1, pp. 85-92, 2001.

[23] T. Hofman, M. Steinbuch, R. M. van Druten, and A. F. A. Serrarens, "A ruled based equivalent fuel consumption minimization strategies for hybrid vehicles," Int. J. Elect. Hybrid Veh., vol. 1, no. 1, pp. 71-94, 2007.

[24] P. Atwood, S. Gurski, and D. Nelson, "Degree of hybridization modeling of a fuel cell hybrid electric sport utility vehicle," presented at the Soc. Automotive Eng. World Congr.-Fuel Cell Transp., Detroit, MI, 2001, SAE Pub. 2001-01-0236.

[25] M. Kim and H. Peng, "Power management and design optimization of fuel cell/battery hybrid vehicles," J. Power Sources, vol. 165, no. 2, pp. 819832, Mar. 2007.

[26] R. Ahluwalia, X. Wang, and A. Rousseau, "Fuel economy of hybrid fuelcell vehicles," J. Power Sources, vol. 152, pp. 233-244, Dec. 2005.

[27] DieselNet, Emission Test Cycles, Jun. 4, 2008. [Online]. Available: http://www.dieselnet.com/standards/cycles/

[28] D. Feroldi, M. Serra, and J. Riera, "Energy management strategies based on efficiency map for fuel cell hybrid vehicles," J. Power Sources, vol. 190, no. 2, pp. 387-401, May 2009.
[29] J. Kessels, "Energy management for automotive power nets," Ph.D. dissertation, Techn. Univ. Eindhoven, Eindhoven, The Netherlands, 2007.

[30] M. Koot, A. Kessels, B. de Jager, W. Heemels, P. van den Bosch, and M. Steinbuch, "Energy management strategies for vehicular electric power systems," IEEE Trans. Veh. Technol., vol. 54, no. 3, pp. 771-782, May 2005.

[31] J. Bernard, S. Delprat, F. Buechi, and T. Guerra, "Global optimization in the power management of a fuel cell hybrid vehicle (FCHV)," in Proc. IEEE Veh. Power Propuls. Conf., 2006, pp. 1-6.

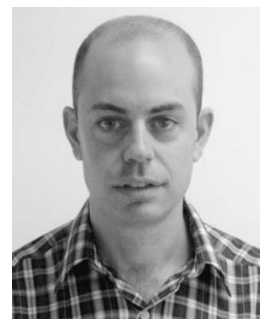

Diego Feroldi received the Electronic Engineering degree from the Universidad Nacional de Rosario, Rosario, Argentina, in 2001 and the Ph.D. degree (summa cum laude) from the Universitat Politècnica de Catalunya (UPC), Barcelona, Spain, in 2009.

$\mathrm{He}$ is currently an Associate Professor with the Department of Automatic Control, UPC, where he is working in the field of fuel-cell control and energymanagement strategies.

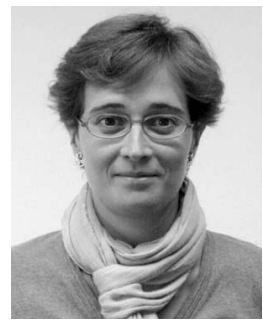

Maria Serra received the Physics degree from the Universitat de Barcelona, Barcelona, Spain, in 1995 and the Ph.D. degree in chemical engineering from the Universitat Politècnica de Catalunya (UPC), Barcelona, in 2000.

She is currently an Associate Professor with the Department of Automatic Control, UPC. Her current scientific work is centered on the modelization and control of fuel-cell systems.

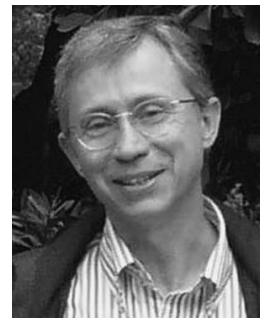

Jordi Riera received the M.Sc. degree in mechanical engineering and the Ph.D. degree in 1985 from the Universitat Politècnica de Catalunya (UPC), Barcelona, Spain.

He is a currently a Full Scientist with the Council of Scientific Research of Spain and an Associate Lecturer with the UPC. His main area of interest is the application of nonlinear control methods to electrical energy generation and conversion systems, particularly fuel cells. 